\title{
Public Coordination and Institution Innovation: An Institutional Approach for Hub-and-Spokes Logistics Network in the Greater Bay Area
}

\author{
Chua Yee Hong ${ }^{*}$, Hao Yu Fan \\ Department of Government and Public Administration, University of Macau, Macau, China \\ Email address: \\ alexchuayeehong@gmail.com (Chua Yee Hong), yhao@umac.edu.mo (Hao Yu Fan) \\ ${ }^{*}$ Corresponding author
}

To cite this article:

Chua Yee Hong, Hao Yu Fan. Public Coordination and Institution Innovation: An Institutional Approach for Hub-and-Spokes Logistics

Network in the Greater Bay Area. Journal of Public Policy and Administration. Vol. 3, No. 2, 2019, pp. 39-48.

doi: 10.11648/j.jppa.20190302.11

Received: April 24, 2019; Accepted: May 29, 2019; Published: June 12, 2019

\begin{abstract}
For several years, the Greater Pearl River Delta (GPRD) has been stagnated under lesser efficient subregional integration proceedings. These cities have been existing economic interdependency which regarding to different economic structures and characteristics. In addition to administrative institution, there are a big difference between Chinese central government and two special administrative regions under the One Country Two Systems. Scholars raise doubts the public coordination and performance and its conjecture, which ties in precisely with the issues of multi-level governance, is based on an empirical study conducted in 9+2 cities in GPRD, which set out to characterize the workings of these territorial innovation systems and to propose a policy strategy are necessary. However, the newly introduction of the Greater Bay Area (GBA) to the GPRD, but the institutional barriers are remaining and need a driver to trigger the innovation for this regional development. This study applies the hub-and-spoke system and private-public agent (PPA) model to utilize the institutional model. Moreover, this study identifies that the integration of logistics in PRD need to be revised after added sense and variation into the new revised gravity model is a better consideration. Meanwhile, this article highlights the hub-and-spoke logistics network, policydriven on institution designs, market-driven on supply chain management, and the institutional innovation. The intracompetition among GBA cities could be eliminated by an integrating hub, as we suggested in this article. Both the essence of the institution or market efficiency, the hub-and-spoke system and PPA model are considerable into GBA development planning regarding its inter-government approach and the liberalized economy at all, whether the problems on tradeoff and distribution are relying on the effective operation of PPA model which undergoing a well-organized institution.
\end{abstract}

Keywords: Public Policy, Greater Bay Area (GBA), Institutional Design, Logistics, Supply-Chain Value

\section{Introduction: GBA and Logistics Industry Development}

Since the 1990s, the "front shop, back factory" regional division of labor established in the 1980s has been expanded to include the growing cross-border movement of low valueadded services from Hong Kong to the Pearl River Delta [1]. Guangdong and Hong Kong and Macao market economies are linked by complex and generally asymmetric structural interdependencies which are assuming larger dimensions with increases in subregional trade and cross-border production. To the date, Guangdong is rich in low-cost resources and possess manufacturing strengths; Hong Kong and Macao offer capital, especially Hong Kong have advanced financial services, sophisticated management skills, and a well-developed legal system. Yang [1] addressed the market players had a critical role in Hong KongPRD ${ }^{1}$ Economic integration, in forms of cross-boundary investment during the period from the late 1970 s to 1997 as market-led economic integration has been proceeded.

1 Pearl River Delta defines as the combination of coastal cities Shenzhen, Zhuhai, Hong Kong and Macau whereas located in the leak of Pearl River Delta. 
Consequently, the partial combination of these economies has already resulted in a tremendous synergy that has placed Great China on a high growth trajectory [2].

\subsection{A Big Picture of Greater Bay Area: An Integration Approach}

The Greater PRD region, however, introduced, constitutes a vast market for consumer goods, but also one of the largest manufacturing and service hubs in the world. Throughout the last 20 years, industrial development and export processing zones, as well as technology parks, have increased, with domestic and foreign enterprises in various industries establishing significant operations and headquarters in the Greater PRD cities. However, the concept of regionalization involves two related processes: de facto processes of economic integration, which are firm-led and network-led processes, and de jure processes of state-led institutionalized governance.

In some observations, the growing economic integration among the Greater PRD economies reflects the triumph of economic forces over political constraints. These outcomes were fostered by the policy of gradual liberalization adopted by China. Guangdong and Hong Kong have agreed on some pilot measures under the Closer Economic Partnership Arrangement (CEPA) to advance trade and investment since 2004. Moreover, China's current Five-Year Plan (2011-15) has given a forceful push to promote PRD's industrial development. Both of the internationalization of the market economy of Hong Kong and the resource-dependent economy of Macao which has constituted a primary form of structural interdependence with Guangdong. These interdependencies have resulted from China's unique policy, which coordinated with 'One Country, Two Systems.'

The Greater PRD is not only a combination of one sovereignty and three independent custom zones but also the initially liberalized economy in China's territories. Regionalization might have exerted significant impacts on cross-border flows of capital and trade flow in the Greater PRD. These developments and economic linkages in this region are vitally and potentially, but also influenced by the policy in which corporate and coordinate, with different interests and social networks.

Efficiency and systematic evolution as industry development and national policies interactively transform markets that are linked unevenly reflect dominant causal factors associated with the strengths of more extensive and more competitive industries, supported in different ways by China's government, especially the state-owned enterprises (SOEs) enjoy many benefits when dealing with Macao and Hong Kong. At the intercorporate level, industry groups coordinate activities between associations of firms. China's government has highlighted interest in the Greater PRD in achieving the high expectation of growth through economic integration with neighboring cities. The intricate networks of interdependency between Guangdong-Hong Kong and Macao, which should make them integrate naturally, but the proceeding always stagnated by the institutional barriers.

\subsection{The Development of Logistics Industry in GBA}

The PRC central government newly introduced Guangdong-Hong Kong-Macao Greater Bay Area (GBA) in 2017. This establishment primarily to further subregional integration into an 'agglomeration cities' in Pearl Region Delta. The provision of promotion infrastructure connectivity has been written on the statement which purposed,

...To strengthen transport links between the Mainland and Hong Kong and Macao, and build an efficient and convenient modern integrated transport system. To leverage the strengths of Hong Kong as an international transportation center, lead other cities in the Bay Area to jointly build world-class port and airport clusters, improve the layout of a motorway, railway, and city rail transit networks, and enhance the connectivity of various modes of transport to provide integrated and efficient transport services. $^{2}$

The economic development in China eastern coastal has been characterized as a high-tech industry and the upper stream of the service supply chain. Hence, the above conditions indicating that the GBA industry has a high demand for the improvement of logistics. According to the World Bank report in 2010, the logistics performance index ${ }^{3}$ (LPI) Indicated that China has been facing a high cost in both inventory and management, but lower in transportation cost. Given the importance of value-added logistics services, as well as participation in subregional or global value chains, requires institution designs to manage the quality of services, custom proceedings and other barriers to trade and transport that could affect the competitiveness of logistics channels.

Most recently, massive spending on infrastructure and transportation will support an increasingly pushing ecommerce. Logistics has become more prominent and is recognized as a critical factor in competitive advantage due to the nature of a physically distributed operations environment and global markets. In short years, Shenzhen has successfully built up an excellent hub for information and communication technologies (ICT) and pushed up the Ecommerce in the GBA. To the date, as $\mathrm{Ng}$ [3] mentioned the

2 'Development Prospects for Guangdong-Hong Kong-Macau Bay Area and the Role of Hong Kong, 'HKTDC, 25 July 2017. https://hkmb.hktdc.com/en/1x0aaxmn/hktdc-research/development-prospects-forguangdong-hong-kong-macau-bay-area-and-the-role-of-hong-kong

3 The international score uses six critical dimensions to benchmark countries' performance and also displays the derived overall LPI index. The scorecard allows comparisons with the world (with the option to display world's best performer) and with the region or income group (with the option to display the region's or income group's best performer) on the six indicators and the overall LPI index. LPI is the weighted average of the country scores on the six key dimensions: 1) Efficiency of the clearance process (i.e., speed, simplicity and predictability of formalities) by border control agencies, including customs; 2) Quality of trade and transport related infrastructure (e.g., ports, railroads, roads, information technology); 3) Ease of arranging competitively priced shipments; 4) Competence and quality of logistics services (e.g., transport operators, customs brokers); 5) Ability to track and trace consignments; 6) Timeliness of shipments in reaching destination within the scheduled or expected delivery time. The scorecards demonstrate the relative performance of all countries (world), regional, and income groups. 
institutional barriers which the electronic customs declaration had solved corresponding to customs for the logistics operators in the PRD. However, another barrier in ecommerce policy and logistics are the enactment of government policies, the uncertainty of judgments of courts and unavailability of details of the law in the PRD. The integrating process in the Greater PRD has been characterized by a troubling degree of terminological and conceptual confusion: what do we mean by institutional governance - or by "the subregional" for that matters? We argue that the pairing matters with the institution and subregional logistics in the GBA.

As described, this article advocates a revision of integrating matters on geographical, economic characters and legal challenge on the 'One Country Two System (OCTS).' First, the PRC's government can link policy-making and institution. Second, it re-introduces the domestic competition for local interest groups and relevance industries into the analysis. Thus, the removal of institutional barriers under the 'one sovereignty and three custom zones' is critical and necessary for further integrating proceeding.

This article explores how does integration matters and trending. Prior research outlines critical implications for ensuring economic benefits from further integration are sustained and associated risks minimized. Specifically, cities in the GBA closest to Hong Kong SAR have been the primary beneficiaries of investment and income growth. The following sections describe the existing institutional barrier and discuss the ways and conditions necessary for the successful operation. We do not only attempt to argue about the varieties of governance approach but also exploring the moves towards a more comprehensive understanding of the development of the GBA.

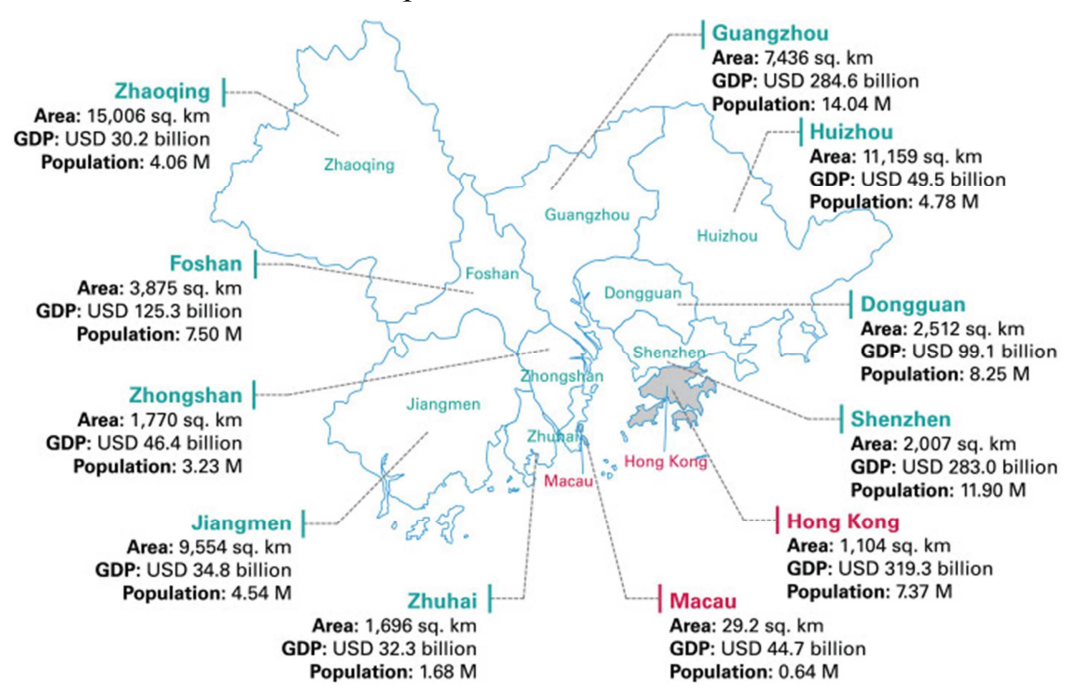

Figure 1. Cities in the Guangdong-Hong Kong-Macao Bay Area.

\section{Literature Reviews}

Bie [4] has pointed out the interdependence among these individual cities in the face of economic globalization has increased dramatically, and this makes some form of future political integration of the two Special Administrative Regions, Hong Kong, and Macao, with mainland GBA all the more crucial. Private sector and civil servants find themselves operating in an ever more complex system of multi-level governance, in which transnational institutional frameworks constrain them.

Kirschen [5] argued that real choice of the instrument from within the set that fit this epistemic and contextual constraint should be made on mostly technical grounds, according to efficiency and cost criteria although the political preferences of interest groups and governments- including sociological and ideological constraints. At the same time, the institutional limitations of the political system itself had to be taken into account as factors influencing key decisionmakers. Some analyst argued that the greater PRD framework is more laborious to integrate than PRD with corresponding different economic gaps and phenomenon. The precise nature of the network management role varies with the type of governance, sector, and stage in the policy process and the competencies required to operate within them also differ in type and intensity [6].

Gronn [7] argues that a variety of structure relations and institutionalized practices are established in an attempt to regularize distributed leadership. For instance, spontaneous collaboration, intuitive working relations, new structures are designed to pool distributed capacities such as task forces and conjoint agencies where individual agents unilaterally transfer the right of control over their actions in the expectation of achieving benefits. Besides, a framework is provided to secure a coincidence of effort, goal, and resources. Distributed leadership is defined regarding the influence attributed voluntarily by organizational members to other individuals, an aggregate of separate individuals to small sets of individuals acting in concert or larger pluralistic member organizational unit [6].

In the logistics works of literature, more attention has been placed on the firm's strategy and performance and lesser 
concentration on the institutional policy. Yan $\mathrm{Hu}$ and Roger [8] reflected that rivalry between cities are commonplace, just as the feverish competition to position cities as hi-tech, logistic hubs without the due consideration of the local strengthen and regional competence. In Ng's study [3], he revealed that logistics operations in the PRD would become much better if the general policy of the government in the PRD has improved in three main areas customs, rules and regulation, and government payments. These are all closely related to the policies of the central or local government.

Upon the transportation network of the GBA, it raised a question that logistics facilities are affected by land price as captioned in the case of the Tokyo Bay Area [9]. It follows that the rise in the landing price needs to be reminded of policymakers. Evaluation is considered here to be a careful and systematic retrospective analysis of the implementation, actions, and results of public policy [10]. Chris and Sheffi [11] have contributed to the development of a useful set of evaluation criteria which can be used to determine the strengths and weakness of a firm's logistics performance measurement system. However, the interconnection of logistics is dependable on the institution-based conditions and policy coordination in the GBA integration.

Khalid and Richard [12] emphasized that a logistics and supply chain management approach to ports may prove of great benefit in underlining the strategic role and future potential of ports within the framework of international business in general. Accordingly, the business circulation of the GBA is relevance to institutional designs in multigovernance and supply value chain in market-led based.

Cheong et al. [13] considered the logistics network design problem with supplier consolidation hubs and multiple shipment options in which they decide on the number, location, and operation of consolidation hubs to minimize the total logistics costs for the network. Shen and Luo [14] revealed the dramatic growth of container port, airport, and logistics industries in Shenzhen has also brought enormous pressure to Hong Kong. $\mathrm{Hu}$ and $\mathrm{Ma}$ [15] has outlined that the entry barrier to commodity market is slow and weakening, but the protection of high-tariff product markets remains strong, and the impediments to crucial production factors are substantial.

On the other hand, there is a pity what little studies which concentrated on the hub-and-spoke system for integrating matters in GBA. Some analyst argued the hub-and-spoke system. However, this ignorance is probably one reason why the slow progress worked in this subregional integration since the late-1990s. Yu An, Yu Zhang and Bo Zeng [16] remind us that the hub-and-spoke paradigm demonstrates significant advantages in improving network connectivity with less number of routes and saving operating cost, the failure of hubs and reactive disruption management could lead to substantial recovery cost to the operator. For this case, the hub-and-spoke network enables to create synergy by the elimination of institutional barrier and agglomeration economies in the GBA. Due to promoting of efficiency on the subregional governance, however, it should be considered into an integrating network under one policy-driven framework in the GBA, either the market-led or governmentled.

As can be seen, a fit model for multilateral government in GBA is demanding. Consequently, the regional integration in GBA has to learn practices from the experience to overcome the co-existing problems, including the institutional barriers and eliminating the internal competition stresses by the GBA cities in the logistics industry.

\section{Action Research on the Gravity Model and the Hub-and-Spoke System}

This study employed the comparative studies analysis is applicable, which added with cross-disciplines on both institutional approach and experimental method. Based on the existing data, this study aims to build up a revised model for explaining the development of GBA's logistics.

As we understand about logistics, it is a multidisciplinary field of study. In a simple context, logistics involves transportation and economic efficiency at all. Logistics have been categorized into commodities and E-commerce. The former one heavier relies on mass transportation, which primary to upstream of supply-chain and manufacturing proceeding. Moreover, the latter logistics are mostly consumption by E-commerce with the end-point. As well as the importance of central to business, this links with the connections of logistics support. Besides, the ICT improvement has advanced the GBA's trade flow but also increased the stresses derivate from the institutional barriers which we need to address it as an essential variable.

\subsection{The Revised Gravity Model}

This study applies a revised gravity model which added institutional variables to interpret the logistics and policy coordination under the GBA framework. Logistics is a conventional gravity interpretation to explain the relationship between economic gravity and trade, in particular to the sources of transport costs. In the economic front, the FTA and trade flow produces the gravity between the economies in the region. Thus, the way to distribute or coordinate the trade flow and logistics are focused on the similar economies in GBA.

The economic gravity is similar to physics gravity model, which drives economic forces into the logistics industry. Generally, the trade cost of the logistics industry in GBA includes transportation cost, labor cost, warehousing cost, border-related cost, and transaction cost. Moreover, the transportation cost is the original cost of around $45 \%$ of cost structure, and it relies on the intensity of infrastructure. A good logistics network as a transportation hub is more accessible to point to point (P2P) destination. Infrastructure development enabling economic integration has been sustained and substantial intending to improve the connectivity of people and the movement of goods and information. 
In the end, infrastructure investment has elevated the competitiveness of the region and improved the quality of life. In all modes of transport, improvements over the past three decades have been astonishing. Road transport that used to be interrupted by endless ferry crossings, especially on western PRD, has quickly evolved from the primitive to the modern age. The difference in interpretation is essential when we consider dynamics and collusion since we will assume that the cost reduction is temporary and therefore, reversible: firms can choose the level of integration each period. This assumption of reversibility would be hard to rationalize in a model where the cost reduction is due to innovation.

For transportation, it considers the gravity model which linking with location planning and the maturity of infrastructure in the region. To clarify, the gravity model using LPI based on six sub-indicators [17] - precisely three referring to institutional design and coordination "regional logistics."

i. The efficiency of the clearance process by customs and other border agencies

ii. Transport and information technology infrastructure

iii.Local logistics industry competence

iv. Ease and affordability of international shipments

v. The facility to track and trace shipments

vi. The timeliness with which shipments reach their destination

The gravity force becomes complicated by these 'linked interest' and 'oligopolistic network' in the greater GBA. Timbergen's gravity model of trade is explaining the effect of bilateral FTA. This study identifies that the integration of logistics in PRD need to be revised after added sense and variation into the new revised gravity model is a better consideration. In this model, $T$ stands for the distribution cost, $D$ stands for the distance between spoke and hub, $I$ stands for the infrastructure index, $G$ stands for the administrative efficiency, and $L$ stands for the logistics worker wage that is being measured. This equation can be changed into a linear form for subregional integration analyses.

Timbergen gravity model of trade:

$$
\mathbf{X}_{i j}=\mathbf{C} .\left[\left(\mathbf{Y}_{i \cdot} \cdot \mathbf{Y}_{j}\right) / \mathbf{D}_{i j}\right]
$$

$\mathbf{X}_{i j}$ : trade flows Y: economic size D: Distance C: Constant

After revised with eliminated institutional barriers and reducing cost on trade cost, the revised gravity model of GBA logistics hub should be

$$
\mathbf{X}_{\mathrm{GBAe} \cdot \mathrm{GBAw}}=\mathbf{C} \cdot\left[\left(\mathbf{Y}_{\mathrm{GBAe}} \cdot \mathbf{Y}_{\mathrm{GBA} \cdot \mathrm{w}}\right) / \mathbf{D}_{\mathrm{GBAe} \cdot \mathrm{GBAw}}\right]
$$

\subsection{The Hub-and-Spoke System in the GBA}

Nicolas Sahuguet and Alexis Walckiers [18] provide a template of hub-and-spoke collusion which implies whereas process the subregional vertical integration in the GBA. To cope with the random variable on local governances which incorporated in the model, cross-border cooperation among $9+2$ cities, the combination of gravity model and the consideration of the hub-and-spoke system is insightful to evaluate the public coordination and performance for the subregional logistic network in the GBA.

There is a need to categorize the logistics into two terms, which is regarding the business segmentation, namely backup manufacturing and express industry in the supply chain of the GBA. The hub-and-spoke system is a model which arranges service delivery assets into a network consisting of an anchor establishment (hub) which offers a full array of services, complemented by secondary establishments (spokes) which offer more limited service arrays, routing commodities needing more intensive services to the hub for consumption.

This study is surmising to determine the significance of trade barrier caused by the subregional logistics in the GBA. The approach can be adapted to any policymaker that is interested in identifying the weak areas of subregional logistics and enhancing its policy coordination under the GBA framework. In practice, boundary spanners are likely to have to engage in tradeoffs between different sources of accountability depending on different circumstances. Additionally, the consequences of being involved in different forms of governance with their different rules, rationales, and accountabilities, are that boundary spanner, particularly the dedicated variety can also face a dilemma of organizational identity [6].

Besides, strategic centralization is the key which unlocks the many benefits of the hub-and-spoke organization design. We notice that a central group initiates and represents business units, funneling up the social strategy to one group. On the other hand, the coordination also mentions how a central group will help to provide a similar experience to other business units. A hub-and-spoke network is not only a centralized, integrated logistics system designed to keep costs down but also the efficiency on subregional governance geographically. Also, the transporting connection demonstrates 'spokes' in the hub-and-spoke system, and included with railway transportation, land transportation, maritime transportation, and combined transportation.

The hub-and-spoke model also enhances an institution's ability to adapt as markets evolve. When attractive markets emerge, cost-efficient satellites facilitate nimble market entry. However, there is a question debunks the policy practices whether the competencies to work in boundary-spanning roles set out above are materially different or similar to those needed to operate within only organizations. There are suggestions in particular that boundary spanners have to switch their behaviors and management styles between different modes of governance.

\section{Public Coordination and Performance in the GBA}

The impletion of 'OCTS' has nearly 20 years in Hong Kong and Macau, but it remains challenges in these two special administrative regions when it toward a new trend. The common challenges have their roots in the production 
activity and legitimate under 'OCTS' faced by the governments in GBA. Also, there has been growing stresses from local communities on the legislature and political elite concerning the distribution of political power between different levels of government. A robust governance structure within the organization which is effective remotely. However, the so-called 'Two Systems" make this advanced economic region complicated with different political environments.

The idea of Osborne and Gaebler [19] has been concerned which introduced a new agenda with 'reinventing government' that propagate a transition from a bureaucratic culture towards an entrepreneurial government which in essence, is high performing, business-like and enabling government. The demands for autonomy and capacity to innovate in modern bureaucracies are rising. On the other hand, the actors' position and roles in the public sector are essential, and it affects the motives for institutional innovation. The minds of Schröter and Wollmann has tackled an innovative idea for the public coordination which implicating the effect of a complex administrative structure, and interest constellation are that public sector reform activities are bound to proceed in a disjointed and incrementalist rather than a comprehensive and 'wholesale' manner' [10].

\subsection{Institutional Barriers}

The mighty works for institutional matters are underlined by two driving forces, namely competing and distribution of interest. The producer (as we addressed non-state actor) and market conditions in GBA are decided by the policymaker, rather than the 'intangible hand' as Adam Smith said. General analyze in political economy, which reflect not only the existence and causal relationship between producer and consumer but also including the government. Theoretically, the Chinese economy is addressed a regulated market economy, but, Hong Kong and Macau are not. If these three different types of economies are forcedly integrated without a buffering stage, there are several conflicts and contradiction is expected, even a market disorder.

The legitimate coordination requires a supra-governmental body under 'OCTS' in GBA, rather than the 'supranational body' as EU integration way. The major obstacle caused the slow progress in GBA integration is an insufficiency of coordination among GBA cities. They are unable to achieve a current dominance whom to lead this subregional integration regards each ambition to maximize their interests. In a simple context, coordination needs to be distributed by interest groups in GBA cities, which relies on their interdependence economy, and even the central government has seated this political economy table. In an economic sense, it has advanced the integrating process by the market-led force. On the other hand, it has stagnated by different institutions under 'OCTS,' in particular to the legitimate coordination of HKSAR and MSAR.

There is a need to address public policies related to logistics facilities, such as land use regulations, development permissions at controlled areas and public support for the development of urban distribution centers would possibly be essential factors for the logistics facility distribution. By contrast, this governance requires a 'crossover' for legitimacy in the GBA.

On the other hand, CEPA almost has eliminated the tariff barrier among GBA cities. However, the non-tariff barriers (NTBs) remain in GBA cities, such as 'sanitary and phytosanitary measures' (SPS). For instance, the different food security measurements resulted in two outcomes: the lesser confidence and prefer confidence in these $9+2$ cities. The case on powder milk regards Chinese mainlander lost their trust in PRC's measurement and chosen transnational purchasing powder milk from HKSAR and MSAR.

\subsection{Institution Design: Eliminating Harmful Competition and Distribution of Interest}

Competing concept and the problems on disparity are another indigenous challenges after the agglomerated in the GBA. It inherits the internal interest conflict among those $9+2$ cities for each economic development. The tech- and capital gap already has separated the western and eastern developing model in each position. That implies the maturity of infrastructure in western GBA and whereas supporting the upstream of the supply chain for coastal cities.

Competition has been categorized into three forms, namely local government, jurisdiction, and industry. The first, this study concentrates on the relationship between GBA citygovernments, which encountering different public interest in the different administrative body. For instance, the competition between Shenzhen and Hong Kong is a unique administrative competition while placing these two cities on comparative politics. Both governments represent different approaches for their citizens on an integrated public policy. A cross-border project requires the policy coordination and funding by different departments tackle several rounds to fix the interest distribution and to protect the public interest in two administrative bodies.

In turn, competition is still seen as the primary means of delivering value for money, and liberalization of markets has been strengthened either in the public or private sector. More importantly, the latter's liberalization of the market is relying on the liberalization of the public sector, which retained conservative interest. As a result, this output becomes much broader than that by government and quasi-market, also involving governance by supply-demand engagement in codesign, co-production, the use of networks. Involving policymakers in co-design and co-production may increase their confidence and so lead to increased participation. So, this is possibly becoming self-reinforcing as confidence builds as a result of experimental integration on administration.

Notably, the market power and market efficiency are underlying the 'legitimacy of PRC' in GBA integrating matters. The concept of 'regulated competition' might improve endogenous and exogenous problems in the GBA and regional development. This session provides a new understanding of what the 'regulated competition' for 
institutional innovation in public administration study. Regulated competition explains the regional-acting driving forces to implement and analyzes the specified conditions of enforcement and implementation of regional governances. Today, there is no such producer could process the production unilaterally, included service sector. Besides, the network of production links up every part of the production, and it also relies on the logistics hub. Insofar, the high autonomy not available to overcome the interest conflicts internally within the GBA region. At all, the different market conditions hardly to negotiate interest distribution for each party.

\subsection{Case Study: The Development of the Logistics Industry in $\boldsymbol{G B} A$}

As described, maritime logistics is an industry that originates from the convergence of maritime transportation and the supply of logistics and distribution services. Hong Kong, Macau, Shenzhen, Zhuhai are traditional costal portcities in the GBA, and the rest western Guangdong cities are beyond these. The geographical location and experimental techniques and capital gathered these captioned cities integrated into the hubs of trade flow and capital flow. In addition to Krugman's new economic geography [20, 21], it clarifies the forces of agglomeration spurred on by economic integration, and it is highly likely that it will increase the territorial disparity. However, the domestic competitions are co-existing in this region.

The critical role of trade flow whereas subjects to logistics as we highlighted in the previous session, to imply which the GBA city to be the hub for the region. When we subject to the competitive infrastructure, there are four cities, namely Shenzhen, Hong Kong, Guangzhou, and Zhuhai are possessed and operated well in the GBA. This offer an excellent location and condition to become the logistics hub in this subregion.

The exception of Hong Kong and Macau, Shenzhen, and Zhuhai also were initialized special economic districts in China which launched 'open door policy' toward foreign investment and international trade. Corresponding to 'free port' and the pooling capital in advanced cities in Hong Kong, Shenzhen and Guangzhou, where implies these cities could establish a joint logistics hub in this subregion. Some institutional barriers exist with the "Free Port" conditions of HKSAR and MSAR, and the rest of GBA cities are not. HKSAR possessing stronger competency on her export and re-export industry, and her wellbeing infrastructure is dependable and support her strengths in logistics hub. According to the feedback from the interviewees in Macau's logistics providers, the free port does not make any contribution or real interests to Macau's logistics and its economy. In relatively, the free port of Hong Kong enhances much benefits and welfares to Macau through the geographical conditions between HK-MAC.

An integrated hub eases the overlapping cost and decreases the intensifying competitiveness among these cities. Chavva and Srinivasa [22] proposed a business intelligent (BI4) tool in helping logistics service providers in achieving strategy formulation. As a result, Hong Kong and Shenzhen performed higher LPI in the GBA, but also the trade flow, either import or export. However, this consequence is predicted to set up the rest of six cities of "9+2", namely Foshan, Zhongshan, Dongguan, Huizhou, Jiangmen, and Zhaoqing as the "spokes," rather than the "hub" for the Greater GBA. $\mathrm{Ng}$ [3] interpreted that the existing policies in e-commerce in the PRD have created dilemmas in further developing e-commerce as well as logistics operations in the PRD and other parts of China. In addition to E-commerce, electronically processing is running well in both business circle and public management. Different measurement and incentive policy drive more people to deal in the web within the testing zone in the GBA, such as Shenzhen.

Moreover, the competitiveness of the logistics operations of the MNEs in China will suffer from the consequences of the barriers to e-commerce policy unless changes are made swiftly to the infrastructure of related policy. Currently, the customs clearing system and administrative processing have been upgraded by the promotion of electronic. Beyond of the trending, logistics become a stronger demand for it. Several problems on the warehousing and transportation were intensified and needed to be solved for the elimination of deadweight costs in the transporting and administrative processes.

Previous studies have proven that a corporatist governance mode is a better institutional design for the GBA due to its economic phenomenon and legitimate. Indeed, on the local government as on the inter-government level, the economic integration process can be analyzed as the result of the political actors under 'OCTS.' For instance, the logistics providers are always complaining the MSAR government has paid lesser efforts on this industry, especially the deepening of seabed for inner harbor located in O Porto Interior. Both reasoning of poor maritime-land infrastructure and the scale of the market, they further weakening the business intelligent in Macau and also facing incremental marginalization stresses from the initiative of GBA when the market competition introduces into Macau. According to the backdrop of logistics providers in Macau, they mostly are registered locally, and fund sourced by the Hong Kong and Chinese capital. In other words, this initiative of GBA under 'OCTS' will drive MSAR government to have to pay more effort on policy to re-build an integrated logistics network with the connection of Macau and GBA cities with market integration and infrastructure sector.

\subsection{Institutional Innovation: Form a Regulative Agency as PPPs Model}

Innovation in public governance is no longer a new mechanism or institutional arrangement which implemented

4 The BI tool comprises data warehousing, OLAP (Online Analytical Processing) and its related supporting system, which analyzes data collected from various sources and then converts it into actionable information. 
to solve the governing problem, but also promoting public interests. Some state-owned enterprises are usually privatized, which reflects state need to regulate for efficiency, fairness, and other such reasons. Western world has entered a new era for public management since the 1980s. Nowadays, the public-private partnerships (PPPs) is no longer a fresh model which represent a particular form of collaborative governance that has steadily grown in popularity in some countries including the US, Australia, and Europe as known as the liberalized economy.

Due to the economic efficiency, economists are always complaining the investment in infrastructure should not be invested by the government. It is because mostly reasoned with the rent-seeking problems and the distribution of political interests. However, many principle-agent problems can also be solved through administrative procedures mandating oversight agency reviews of government actions [23].

Regarding the economical features and political conditions, PPPs is compatible as a mechanism to lever in more integrative resources and private sector disciplines into the public sector. Moreover, PPPs have been used to construct substantial and long-term infrastructure contracts in western economies. Pollock [24] has debated the potential of PPPs, particularly in relations to their long-term financial implication. However, we purpose this PPPs model is dominated by the private sector rather than the public. Naturally, there are some organizational and managerial challenges remaining in PPPs model. Also, it requires enormous input upon the negotiation table and more difficult by the number of actors involved in the process, the multiple forms of accountability stemming from different parties and value base emanating from the public sector and private sector interests [25].

\subsection{The PPA in the GBA: Market Efficiency and the Removal from Institutional Barriers}

The agency plays a significant and increasing role in designing and coordinating policies and policy-making, ensuring accountability to legislatures and controlling the budgets, activities, and plan of line departments and ministries [26]. For this case, we initiate that a private-public agency (PPA) which is a public body whose duties are set down in legislation for the regional integration in GBA.

Regarding the legitimate differences between Chinese, HKSAR, and MSAR, we suppose with the adding the administrative hearing which is conducted by tribunals in a quasi-judicial fashion, often in order to aid tribunals in their activities. Public participation through hearings is the most common type of public or network consultation in many sectors. In relatively, it is a few public hearings be proceeded in economic matters in Hong Kong and Macau, even the Chinese cities in past decades.

For this initiative, we believe that the agency body enables a dynamic part of inter-governmental regulating functional and technical factors of governance. Also, this specific form of governance like the market or corporatist modes are high levels of intrusiveness can diminish their appeal in the eyes of policy designers. On the other hand, policy coordination requires a high density of communication among the involving local governments and two SAR government. Initiative for an authority which forms up by the mentioned government is believed to execute policy coordination under the GBA framework.

PPA is a co-shareholding term to play its managing roles and integrating by both inter-government approach and private operating approach. The GBA government is back up for PPA's policy coordination and PPA running its best performance with market effectiveness and integrating effects. GBA governments raise the 'trust' fund for the PPA according to the GDP-based ratio and the evaluation by the Hong Kong and Macau Affairs Office of State Council. The organizational chart of PPA is critical to the hub-and-spoke system in GBA framework.

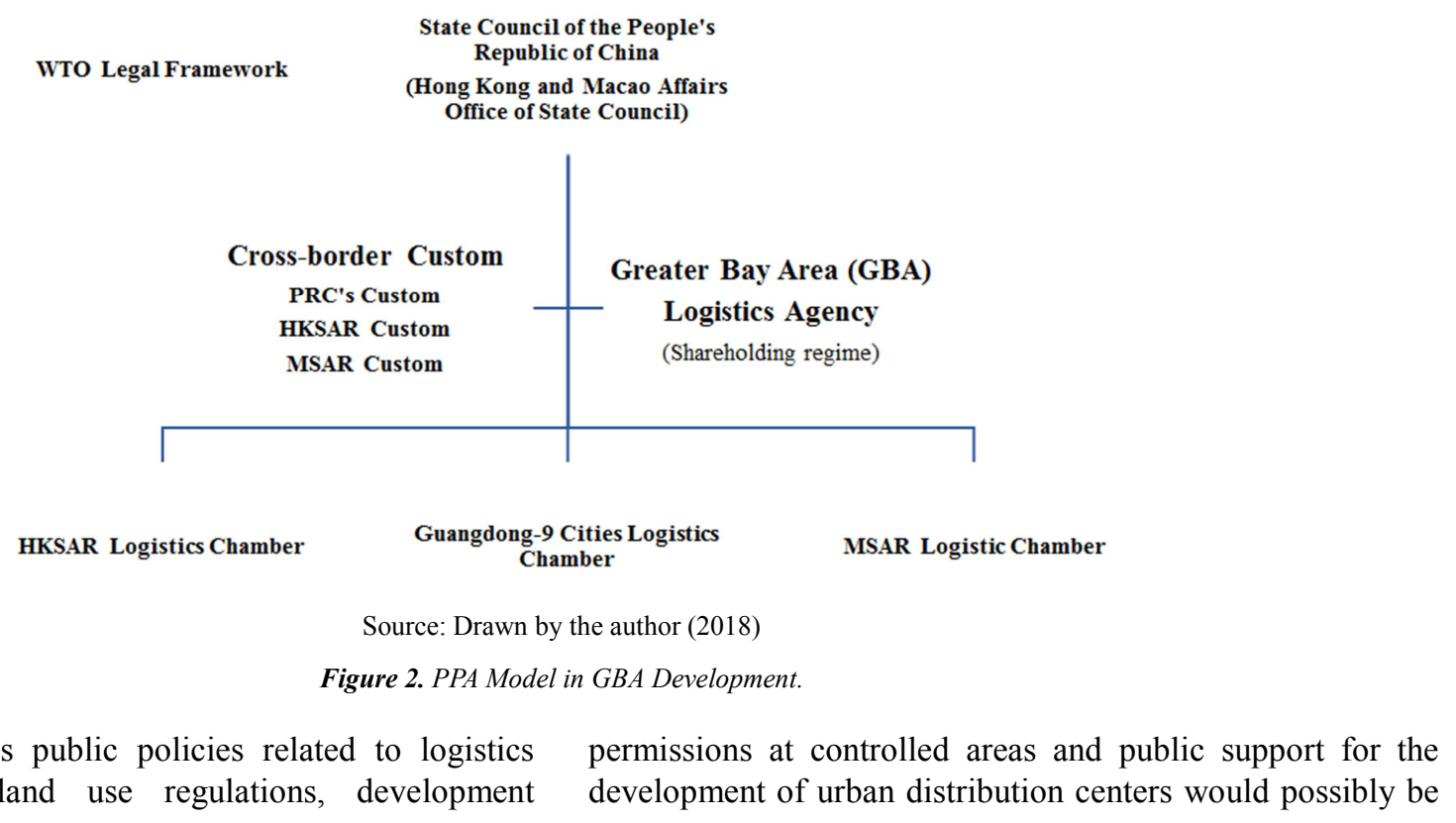

We have to address public policies related to logistics facilities, such as land use regulations, development development of urban distribution centers would possibly be 
essential factors for the logistics facility distribution.

Marketization is a trend for the integration in GBA. It also a conventional driving force for three custom zones under OCTS. GBA logistics agency is assigned the mission to shorten transportation cost and enhance efficiency by 'market conditions' and minimize the deadweight loss caused by the increasing numbers of logistics providers. By contrast, this governance requires a 'crossover' for legitimacy in the GBA. In this case, PPA can play a role in enhancing competencies and skills in the logistics sectors.

There is a suggestion that a regulated number of providers in GBA's logistic industry probably an excellent concept to promote efficiency with synergy effect. At least, the sharing logistic network and labors are expected to running orderly, rather than the congestion of infrastructure and costly under full spreading competitions. The complementary infrastructure of transportation and distribution of logistics network also in charge by the PPA in GBA. Above term and conditions are revised under the "one country, two systems' framework and enhance the accountability to the public in the GBA. In particular, public hearings can improve the people's confidences and policy coordination between the private and public sector.

\section{Findings and Discussion}

Given the above, our findings are combined with lower efficiency in economic activity and the reflection of demand for institution innovation in GBA. The facts demonstrate that the maritime logistic cost between Guangdong-Hong Kong and Macau are far higher than land delivery and need more working days. On the other hand, maritime logistics is no longer competitive, but land delivery, especially the emergence of express delivery in today's logistics. 3PL logistics were keep growing and innovating with the emergence of e-retailing too. Although, the Guangdong cities as a backup of a manufacturing base for GBA, also continually refueling the regional trade and routing in this regional supply chain network. On the logistics cost approach, many SMEs have massive cost on business connections, for instance, the labor cost and warehousing cost, particular to Macau. Although the entirely road-transportation and maritime-transportation cost have been cost down by the economy of scale, and the labor costs of logistics have been raised since the e-commerce emerged in a few years.

The full number of logistics provider has increased the competition and resulting in the market efficiency issue in GBA. There is a need to integrate and operate by the PPA model. A further issue relates to relationships with customers. It is clear from the interviews that the demand for 3PL is growing as manufacturers seek to divest themselves of many labor-intensive and non-core logistics functions. These findings extract that a duo-hubs-and-spoke system, namely western-led by Zhongshan and eastern hub led by Hong Kong. Cost drive up the subregional integration in the GBA although the landing cost is expensive and scarcity in these two advanced cities.

\section{Conclusion}

The hub-and-spoke organization design has dramatically facilitated logistics in GBA, and those efforts to operate in a fiscally responsible and highly effective manner. The incremental labor cost has driven the logistics to advance ICT. The saving cost from transportation also promoted the efficiency of GBA's logistics. The hub-and-spoke system not only enables to decrease in the cost of transportation among the GBA cities but also enhancing market efficiency by the agglomeration effect as Paul Krugman captioned in geographical location.

Meanwhile, the intra-competition among GBA cities could be eliminated by an integrating hub, as we suggested in this article. PPA model enables to lower transaction costs by both approaches, either horizontal or vertical integration in industrial structure. More significantly, the vertical integration strategy became very popular with increasing online shopping - also, the horizontal integration help to promote market efficiency by elimination of inefficiency corporation in GBA.

However, the institutional barriers which mentioned with legitimate problems are remained and require an active and dominating agency to lead the integration in GBA economy rather than a paper of policy. This article assesses the role of PPA in GBA through the work of the class of actors known as 'hub' of collective interests - actors who operate in multiorganizational and multi-sectoral environments. Another issue should be well considered that when a higher potential for legal repercussion due to size (such as an organization may become a monopoly). Both the essence of the institution or market efficiency, the hub-and-spoke system and PPA model are considerable into GBA development planning regarding its inter-government approach and the liberalized economy at all, whether the problems on tradeoff and distribution are relying on the effective operation of PPA model which undergoing a well-organized institution.

\section{Acknowledgements}

This research was supported by the University of Macau which titled as Post-doctoral Fellow for the UM Funded project "An Empirical Research on the Regional Integration Development between Macau and the Greater Pearl River Delta (GPRD) with the Faculty of Social Sciences.

\section{References}

[1] Yang, C. (2004). From market-led to institution-based economic integration: The case of the Pearl River Delta and Hong Kong. Issues \& studies, 40 (2), 79-118.

[2] Yin-Wong Cheung, M. D. (2007). The Economic Integration of Greater China: Real and Financial Linkages and the Prospects for Currency Union. Hong Kong: Hong Kong University Press.

[3] Ng, J. (2009). Barriers to e-commerce policy in logistics: an exploratory study of the Pearl River Delta, China. International Journal of Logistics: Research and Applications, 12 (3), 195-212. 
[4] Bie, J. M. (2015). Greater Pearl River Delta: Historical Evolution towards a Global City-Region. Journal of Urban Technology, 22 (2), 103-23.

[5] Kirschen, E. S. (1964). Economic Policy in Our Time. Chicago, IL: Rand McNally.

[6] Williams, P. (2012). Collaboration in public policy and practice: perspectives on boundary spanners. UK: The Policy Press.

[7] Gronn, P. (2002). Distributed leadership as a unit of analysis. Leadership Quarterly, 13, 423-451.

[8] Hu, Y. a. (2002). Globalization, Governance, and Development of the Pearl River Delta Region. China Review, $2(1), 61-83$.

[9] Takanori Sakai, K. K. (2016). Logistics facility distribution in Tokyo Metropolitan area: Experiences and policy lessons. Transportation Research Procedia, 12, 263-277.

[10] Vedung, E. (1997). Public Policy and Program Evaluation. NJ: Transaction Publishers. Wollmann, E. S., (1997). Public Sector Reforms in Germany: whence and where?A case of ambivalence. Hallinan Tutkimus, 3, 184-200.

[11] Chris, C. a. (1995). A Review and Evaluation of Logistics Performance Measurement Systems. The International Journal of Logistics Management, 6 (1), 61-74.

[12] Khalid, B. a. (2004). A logistics and supply chain management approach to port performance measurement. Maritime Policy \& Management, 31 (1), 47-67.

[13] Cheong, M. L., Bhatnagar, R., \& and Graves, S. (2007). Logistics Network Design with Supplier Consolidation Hubs and Multiple Shipment Options. Journal of Industrial and Management Optimization, 3 (1), 51-69.

[14] Shen, J. a. (2013). From Fortress Hong Kong to Hong KongShenzhen Metropolis: the emergence of government-led strategy for regional integration in Hong Kong. Journal of Contemporary China, 22 (84), 944-965.

[15] Ma, D. H. (2011). Government Power and its Impact on PanPearl River Delta Regional Cooperation: Cooperative
Networks and Regional Governance. In J. X. Anthony G. O. Yeh, China's Pan-Pearl River Delta: Regional Cooperation and Development. Hong Kong: Hong Kong University Press.

[16] Yu An, Y. Z., (2015, July). The reliable hub-and-spoke design problem: Models and algorithms. Transportation Research Part B: Methodological, 77, 103-122.

[17] Arvis, J.-F. M. (2007). Connecting to Compete in 2007: Trade Logistics in the Global Economy. Washington, DC: World Bank.

[18] Sahuguet Nicolas., a. W., (2016). A theory of hub-and-spoke collusion. International Journal of Industrial Organization, 53 (2017), 353-370.

[19] Osborne, D. \&. (1992). Reinventing Government. How the Entrepreneurial Spirit is Transforming the Public Sector. MA: Addison-Wesley Publishing.

[20] Krugman, P. (1991). Geography and Trade. Cambridge: MA: MIT Press.

[21] Krugman, P. (1991). Increasing Return. The Journal of Political Economy and Economic Geography, 99 (3), 483-499.

[22] Chavva Subba Reddy, Ravi Sankar Sangam, and B. Srinivasa Rao. (2019). A Survey on Business Intelligence Tools for Marketing, Financial, and Transportation Services. In R. S. Chavva Subba Reddy, Smart Intelligent Computing and Applications (pp. 495-504). Singapore: Springer.

[23] McCubbins, M. D. (1987). Administrative Procedures as Instruments of Political Control. Journal of Law, Economics, and Organization, 3 (2), 243-277.

[24] . Pollock, A. P. (2007, April). An Examination of the UK Treasury' evidence base for cost and time overturn data in UL value-for-money policy and appraisal. Public Money and Management, 122-133.

[25] Klijn, E.-H. a. (2003, July). Institutional and strategic barriers to public-private partnership: an analysis of Dutch cases. Public Money and Management, 137-146.

[26] Howlett, M. (2011). Designing Public Policies: principles and instruments. New York: Routledge.

i. The "Greater Bay Area" refers to the Chinese government's scheme to link the cities of Hong Kong, Macau, Guangzhou, Shenzhen, Zhuhai, Foshan, Zhongshan, Dongguan, Huizhou, Jiangmen, and Zhaoqing into an integrated economic and business hub. Additionally, the GBA is newly replacement of PRD, and they are equivalent in many studies, only different from the cited literature before 2017. 